\title{
Regulation and Feedback of Cholesterol Metabolism
}

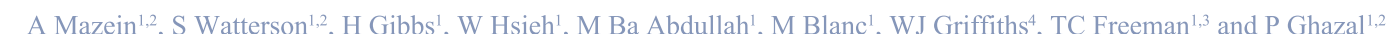

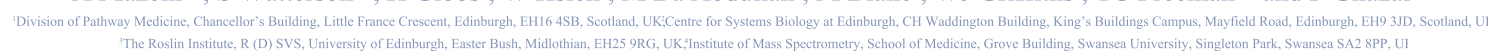
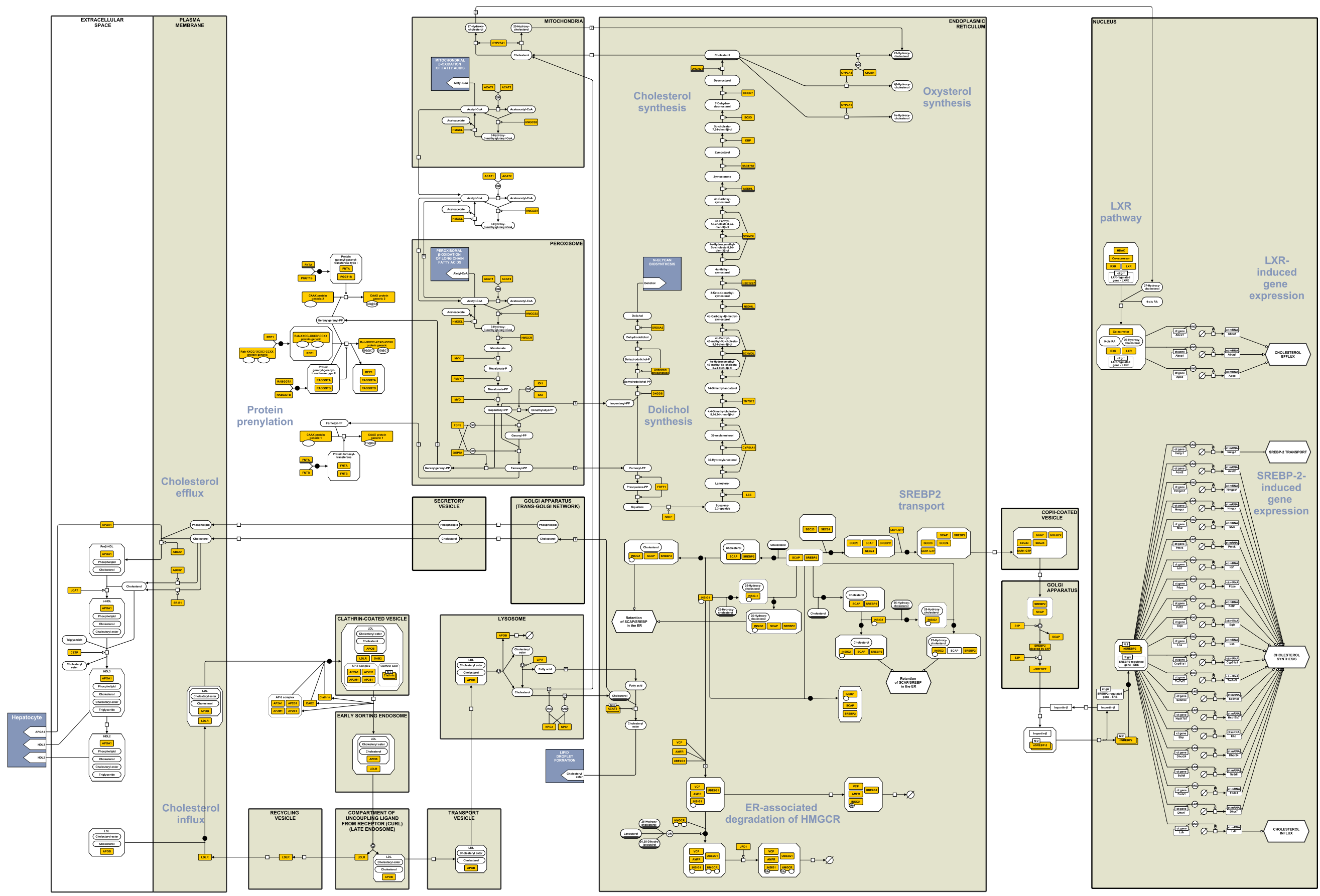


\title{
Regulation and feedback of cholesterol metabolism A Mazein ${ }^{1,2}$, S Watterson ${ }^{1,2}$, H Gibbs ${ }^{1}$, W Hsieh ${ }^{1}$, M Ba Abdullah ${ }^{1}$, M Blanc ${ }^{1}$, WJ Griffiths ${ }^{4}$, TC Freeman ${ }^{1,3}$ and P Ghazal ${ }^{1,2}$
}

\begin{abstract}
${ }^{1}$ Division of Pathway Medicine, University of Edinburgh, Chancellor's Building, Little France Crescent, Edinburgh, EH16 4SB, UK, ${ }^{2}$ Centre for Systems Biology at Edinburgh, University of Edinburgh, $\mathrm{CH}$ Waddington Building, King's Buildings Campus, Mayfield Road, Edinburgh, EH9 3JD, UK, ${ }^{3}$ The Roslin Institute, R (D) SVS, University of Edinburgh, Easter Bush, Midlothian, EH25 9RG, UK ${ }^{4}$ Institute of Mass Spectrometry, School of Medicine, Grove Building, Swansea University, Singleton Park, Swansea SA2 8PP, UK.
\end{abstract}

Cholesterol biosynthesis serves as a central metabolic hub for numerous biological processes in health and disease. An integrative knowledge representation of how the cholesterol pathway is structured and how it interacts with other pathway systems is lacking. Here we provide using Systems Biology Graphical Notation the research synthesis of a process diagram integrating the regulatory and feedback systems for cholesterol synthesis.

Cholesterol is an intensively studied, multi-functional lipid that is key to many aspects of immunological, neuronal, viral and hepatocyte biology. It is an essential component of cellular membranes and is a precursor to steroids, bile acids and vitamin D whilst its own precursors contribute to prenylation and dolichylation. As a consequence of its broad role, tightly regulated mechanisms have evolved to ensure intracellular homeostasis of the cholesterol biosynthesis pathway.

Despite the importance of the sterol biosynthesis pathway to cellular function and its value in pharmaceutical therapies, an integrative picture of how the pathway is structured and how it interacts with other pathway systems has not been well described in the literature.

Here, we present a pathway diagram that provides an integrative consensus view of the current level of understanding of the sterol biosynthesis pathway, its relationship with other pathways of note and its associated feedback mechanisms. This model of the sterol biosynthesis pathway has been assembled using a variety of publicly available resources including the research findings of the LipidMaps consortium (http://www.lipidmaps.org) and results obtained from thorough searches of the published literature that have been manually curated and validated by domain experts. It is most relevant to macrophage biology.

The model that we present here is described using the Systems Biology Graphical Notation ${ }^{1}$ (SBGN), a community driven consensus graphical schema for capturing the molecular details of pathway systems, although many other schema exist that can be used to provide alternative descriptions, such as $\mathrm{mEPN}^{2}$. The Systems Biology Graphical Notation Process Description language Level 1 scheme $^{3}$ was used in a slightly modified form. We used a different shape for simple chemicals in order for compound names to fit within. The pathway names such as "cholesterol synthesis" or "SREBP transport" are also not a part of SBGN PD language and are used on the scheme for the readers' benefit.

Together with the SBGN model, we include a simplified schematic that shows the relationship between the pathway subsystems that are related to cholesterol biosynthesis. 


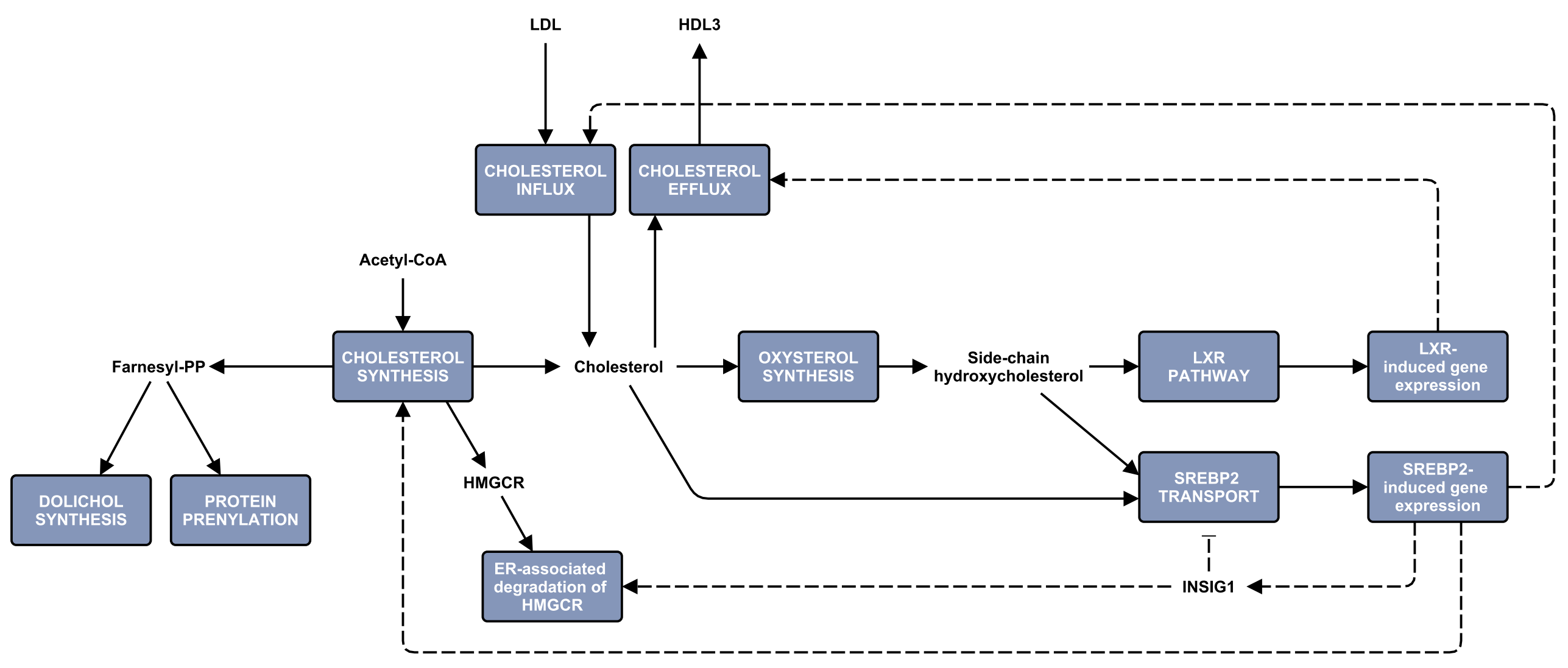


The model can be broadly described as a system that combines: cholesterol influx, cholesterol efflux, protein prenylation, dolychol synthesis, cholesterol synthesis, ER associated degradation of HMGCR, SREBP2 transport, oxysterol synthesis, the LXR pathway, SREBP2-induced gene expression and LXR-induced gene expression.

We also include a list of the published literature from which the model has been assembled and a list of UniProt Ids for the proteins captured in the model.

This is a multi-scale model that captures the details of absorption and efflux of cholesterol between the cell and the blood plasma. However, it is not completely exhaustive. The LDL and VDL transports systems are not captured. It describes the cholesterol processing that occurs in each organelle of the cell and the transcriptional control that mediates feedback to ensure cholesterol homeostasis.

Cholesterol biosynthesis itself constitutes a sequence of metabolic transitions that occur across several organelles, starting with the processing of acetyl-CoA in the mitochondria. This pathway branches into the protein prenylation arm, which has been shown to be critical to optimal CMV infection ${ }^{4}$, and the sterol arm that is responsible for cholesterol production. Feedback occurs through SREBP2 transport. The SCAP:SREBP2 complex, which ordinarily is chaperoned to the nucleus to activate the suite of enzymes associated with the cholesterol biosynthesis pathway, is instead retained in the endoplasmic reticulum, in the presence of relatively high concentrations of intracellular cholesterol or side-chain hydroxylated cholesterol, in particular 25hydroxycholesterol. This acts to down-regulate transcription of the enzymes acting on the sterol biosynthesis pathway until ordinary levels of cholesterol and its derivatives have been reached.

It has been reported that SCAP:SREBP2 is significantly retained when cholesterol concentration exceeds $5 \%$ of total endoplasmic reticulum lipids ${ }^{5}$ However, it would appear that the sensitivity of the feedback mechanism to sterol levels is dependent on expression as overexpression of Insig- 1 has been shown to lower this threshold to $3 \%{ }^{5}$.

INSIG1 is transcriptionally dependent on SREBP2, while INSIG2 is not $^{6}$. When intracellular cholesterol rises, we would expect SREBP2 retention to lead to a fall in de novo INSIG1 synthesis. As the free and unbound INSIG1 protein declines, this would lead to INSIG2 becoming dominant in the process of SREBP2 retention. Differences between the affinity of INSIG1 and INSIG2 for complex formation will emerge at this point as a change to the feedback sensitivity. As cholesterol levels start to fall, retained SREBP2 will be increasingly transported to the nucleus, boosting INSIG1 synthesis and restoring the pool of INSIG1 protein available to respond to further fluctuations in cholesterol levels.

This regulation impacts not just upon cholesterol, but also upon the oxysterols downstream of cholesterol and upon the LXR genes, downstream of the oxysterols. In the diagram presented, the transcriptional output of the genes affected has not been directly connected to the corresponding enzymes in the cholesterol biosynthesis pathway for the benefit of clarity.

We hope that by elucidating and integrating the details of this pathway and its context, this will form the basis of a finer level of understanding of the pathway and its function and that this will add a greater insight to future studies of the sterol biosynthesis pathway.

${ }^{1}$ Le Novere et al. Nature Biotechnology 27, 735 - 741 (2009).

${ }^{2}$ Freeman et al. BMC Systems Biology 4, 65 (2010).

${ }^{3}$ Moodie et al.Nature Precedings http://dx.doi.org/10.1038/npre.2011.3721.4 (2011). 
${ }^{4}$ Blanc et al. PLoS Biology 9(3), e1000598 (2011).

${ }^{5}$ Radhakrishnan et al. Cell Metabolism 8, 512 - 521 (2008).

${ }^{6}$ Yabe et al. Proceedings of the National Acadamy of Sciences USA 100(6), 3155-3160 (2003).

\section{Acknowledgements}

CSBE is a Centre for Integrative Systems Biology funded by BBSRC and EPSRC award D019621. This work was supported by Wellcome Trust program grant WT066784 (to PG). 


\section{References}

\section{Cholesterol synthesis}

Do, R., Kiss, R.S., Gaudet, D. and Engert, J.C. (2009) Squalene synthase: a critical enzyme in the cholesterol biosynthesis pathway. Clin Genet, 75, 19-29.

Kovacs, W.J. and Krisans, S. (2003) Cholesterol biosynthesis and regulation: role of peroxisomes. Adv Exp Med Biol, 544, 315-327.

Kovacs, W.J., Olivier, L.M. and Krisans, S.K. (2002) Central role of peroxisomes in isoprenoid biosynthesis. Prog Lipid Res, 41, 369-391.

Kovacs, W.J., Tape, K.N., Shackelford, J.E., Duan, X., Kasumov, T., Kelleher, J.K., Brunengraber, H. and Krisans, S.K. (2007) Localization of the pre-squalene segment of the isoprenoid biosynthetic pathway in mammalian peroxisomes. Histochem Cell Biol, 127, 273290.

Krisans, S.K. (1996) Cell compartmentalization of cholesterol biosynthesis. Ann N Y Acad Sci, 804, 142-164.

Moebius, F.F., Fitzky, B.U. and Glossmann, H. (2000) Genetic defects in postsqualene cholesterol biosynthesis. Trends Endocrinol Metab, 11, 106-114.

The LIPID MAPS - Nature Lipidomics Gateway, http://www.lipidmaps.org/

Waterham, H.R. (2006) Defects of cholesterol biosynthesis. FEBS Lett, 580, 5442-5449.

Waterham, H.R. and Wanders, R.J. (2000) Biochemical and genetic aspects of 7dehydrocholesterol reductase and Smith-Lemli-Opitz syndrome. Biochim Biophys Acta, 1529, 340-356.

\section{Oxysterol synthesis}

Bjorkhem, I. (2002) Do oxysterols control cholesterol homeostasis? J Clin Invest, 110, 725-730.

Eaton, S. (2008) Multiple roles for lipids in the Hedgehog signalling pathway. Nat Rev Mol Cell Biol, 9, 437-445.

Honda, A., Yamashita, K., Hara, T., Ikegami, T., Miyazaki, T., Shirai, M., Xu, G., Numazawa, M. and Matsuzaki, Y. (2009) Highly sensitive quantification of key regulatory oxysterols in biological samples by LC-ESI-MS/MS. J Lipid Res, 50, 350-357.

Norlin, M., von Bahr, S., Bjorkhem, I. and Wikvall, K. (2003) On the substrate specificity of human CYP27A1: implications for bile acid and cholestanol formation. J Lipid Res, 44, 15151522.

Norlin, M. and Wikvall, K. (2007) Enzymes in the conversion of cholesterol into bile acids. Curr Mol Med, 7, 199-218.

Russell, D.W. (2000) Oxysterol biosynthetic enzymes. Biochim Biophys Acta, 1529, 126-135. 


\section{Dolichol synthesis}

Cantagrel, V., Lefeber, D.J., Ng, B.G., Guan, Z., Silhavy, J.L., Bielas, S.L., Lehle, L., Hombauer, H., Adamowicz, M., Swiezewska, E., De Brouwer, A.P., Blumel, P., SykutCegielska, J., Houliston, S., Swistun, D., Ali, B.R., Dobyns, W.B., Babovic-Vuksanovic, D., van Bokhoven, H., Wevers, R.A., Raetz, C.R., Freeze, H.H., Morava, E., Al-Gazali, L. and Gleeson, J.G. (2010) SRD5A3 is required for converting polyprenol to dolichol and is mutated in a congenital glycosylation disorder. Cell, 142, 203-217.

Endo, S., Zhang, Y.W., Takahashi, S. and Koyama, T. (2003) Identification of human dehydrodolichyl diphosphate synthase gene. Biochim Biophys Acta, 1625, 291-295.

Jones, J., Viswanathan, K., Krag, S.S. and Betenbaugh, M.J. (2005) Polyprenyl lipid synthesis in mammalian cells expressing human cis-prenyl transferase. Biochem Biophys Res Commun, 331, 379-383.

Jones, M.B., Rosenberg, J.N., Betenbaugh, M.J. and Krag, S.S. (2009) Structure and synthesis of polyisoprenoids used in N-glycosylation across the three domains of life. Biochim Biophys Acta, 1790, 485-494.

Shridas, P., Rush, J.S. and Waechter, C.J. (2003) Identification and characterization of a cDNA encoding a long-chain cis-isoprenyltranferase involved in dolichyl monophosphate biosynthesis in the ER of brain cells. Biochem Biophys Res Commun, 312, 1349-1356.

\section{Protein prenylation}

Fukuda, M. (2008) Regulation of secretory vesicle traffic by Rab small GTPases. Cell Mol Life Sci, 65, 2801-2813.

Kanno, E., Ishibashi, K., Kobayashi, H., Matsui, T., Ohbayashi, N. and Fukuda, M. (2010) Comprehensive screening for novel rab-binding proteins by GST pull-down assay using 60 different mammalian Rabs. Traffic, 11, 491-507.

Maurer-Stroh, S., Koranda, M., Benetka, W., Schneider, G., Sirota, F.L. and Eisenhaber, F. (2007) Towards complete sets of farnesylated and geranylgeranylated proteins. PLoS Comput Biol, 3, e66.

\section{SREBP-2 transport}

Dong, X.Y. and Tang, S.Q. (2010) Insulin-induced gene: a new regulator in lipid metabolism. Peptides, 31, 2145-2150.

Espenshade, P.J., Li, W.P. and Yabe, D. (2002) Sterols block binding of COPII proteins to SCAP, thereby controlling SCAP sorting in ER. Proc Natl Acad Sci U S A, 99, 11694-11699.

Fernandez-Hernando, C., Suarez, Y., Rayner, K.J. and Moore, K.J. (2011) MicroRNAs in lipid metabolism. Curr Opin Lipidol, 22, 86-92.

Irisawa, M., Inoue, J., Ozawa, N., Mori, K. and Sato, R. (2009) The sterol-sensing endoplasmic reticulum (ER) membrane protein TRC8 hampers ER to Golgi transport of sterol regulatory element-binding protein-2 (SREBP-2)/SREBP cleavage-activated protein and reduces SREBP-2 cleavage. J Biol Chem, 284, 28995-29004.

Nohturfft, A. and Zhang, S.C. (2009) Coordination of lipid metabolism in membrane biogenesis. Annu Rev Cell Dev Biol, 25, 539-566. 
Radhakrishnan, A., Goldstein, J.L., McDonald, J.G. and Brown, M.S. (2008) Switch-like control of SREBP-2 transport triggered by small changes in ER cholesterol: a delicate balance. Cell Metab, 8, 512-521.

Sato, R. (2009) SREBPs: protein interaction and SREBPs. Febs J, 276, 622-627.

Sato, R. (2010) Sterol metabolism and SREBP activation. Arch Biochem Biophys, 501, 177-181.

Sun, L.P., Li, L., Goldstein, J.L. and Brown, M.S. (2005) Insig required for sterol-mediated inhibition of Scap/SREBP binding to COPII proteins in vitro. J Biol Chem, 280, 26483-26490.

Sun, L.P., Seemann, J., Goldstein, J.L. and Brown, M.S. (2007) Sterol-regulated transport of SREBPs from endoplasmic reticulum to Golgi: Insig renders sorting signal in Scap inaccessible to COPII proteins. Proc Natl Acad Sci U S A, 104, 6519-6526.

Yabe, D., Komuro, R., Liang, G., Goldstein, J.L. and Brown, M.S. (2003) Liver-specific mRNA for Insig-2 down-regulated by insulin: implications for fatty acid synthesis. Proc Natl Acad Sci $U S A, 100,3155-3160$.

\section{ER-associated degradation of HMGCR}

Bengoechea-Alonso, M.T. and Ericsson, J. (2007) SREBP in signal transduction: cholesterol metabolism and beyond. Curr Opin Cell Biol, 19, 215-222.

Cao, J., Wang, J., Qi, W., Miao, H.H., Wang, J., Ge, L., DeBose-Boyd, R.A., Tang, J.J., Li, B.L. and Song, B.L. (2007) Ufd1 is a cofactor of gp78 and plays a key role in cholesterol metabolism by regulating the stability of HMG-CoA reductase. Cell Metab, 6, 115-128.

DeBose-Boyd, R.A. (2008) Feedback regulation of cholesterol synthesis: sterol-accelerated ubiquitination and degradation of HMG CoA reductase. Cell Res, 18, 609-621.

Jo, Y. and Debose-Boyd, R.A. (2010) Control of cholesterol synthesis through regulated ERassociated degradation of HMG CoA reductase. Crit Rev Biochem Mol Biol, 45, 185-198.

Lee, J.N., Song, B., DeBose-Boyd, R.A. and Ye, J. (2006) Sterol-regulated degradation of Insig1 mediated by the membrane-bound ubiquitin ligase gp78. J Biol Chem, 281, 39308-39315.

Song, B.L., Sever, N. and DeBose-Boyd, R.A. (2005) Gp78, a membrane-anchored ubiquitin ligase, associates with Insig-1 and couples sterol-regulated ubiquitination to degradation of HMG CoA reductase. Mol Cell, 19, 829-840.

\section{SREBP-2-induced gene expression}

Edwards, P.A., Tabor, D., Kast, H.R. and Venkateswaran, A. (2000) Regulation of gene expression by SREBP and SCAP. Biochim Biophys Acta, 1529, 103-113.

Horton, J.D. (2002) Sterol regulatory element-binding proteins: transcriptional activators of lipid synthesis. Biochem Soc Trans, 30, 1091-1095.

Horton, J.D., Shah, N.A., Warrington, J.A., Anderson, N.N., Park, S.W., Brown, M.S. and Goldstein, J.L. (2003) Combined analysis of oligonucleotide microarray data from transgenic and knockout mice identifies direct SREBP target genes. Proc Natl Acad Sci U S A, 100, 12027 12032.

Shimano, H. (2000) Sterol regulatory element-binding protein-1 as a dominant transcription factor for gene regulation of lipogenic enzymes in the liver. Trends Cardiovasc Med, 10, 275 278. 
Shimano, H. (2001) Sterol regulatory element-binding proteins (SREBPs): transcriptional regulators of lipid synthetic genes. Prog Lipid Res, 40, 439-452.

Shimano, H. (2002) Sterol regulatory element-binding protein family as global regulators of lipid synthetic genes in energy metabolism. Vitam Horm, 65, 167-194.

Weber, L.W., Boll, M. and Stampfl, A. (2004) Maintaining cholesterol homeostasis: sterol regulatory element-binding proteins. World J Gastroenterol, 10, 3081-3087.

\section{LXR pathway}

Desvergne, B., Michalik, L. and Wahli, W. (2006) Transcriptional regulation of metabolism. Physiol Rev, 86, 465-514.

Edwards, P.A., Kennedy, M.A. and Mak, P.A. (2002) LXRs; oxysterol-activated nuclear receptors that regulate genes controlling lipid homeostasis. Vascul Pharmacol, 38, 249-256.

Edwards, P.A., Kennedy, M.A. and Mak, P.A. (2002) LXRs; oxysterol-activated nuclear receptors that regulate genes controlling lipid homeostasis. Vascul Pharmacol, 38, 249-256.

Smirnov, A.N. (2010) Lipid signaling in the atherogenesis context. Biochemistry (Mosc), 75, 793-810.

Torocsik, D., Szanto, A. and Nagy, L. (2009) Oxysterol signaling links cholesterol metabolism and inflammation via the liver X receptor in macrophages. Mol Aspects Med, 30, 134-152.

Zhao, C. and Dahlman-Wright, K. (2010) Liver X receptor in cholesterol metabolism. $J$ Endocrinol, 204, 233-240.

\section{LXR-induced gene expression}

Beyea, M.M., Heslop, C.L., Sawyez, C.G., Edwards, J.Y., Markle, J.G., Hegele, R.A. and Huff, M.W. (2007) Selective up-regulation of LXR-regulated genes ABCA1, ABCG1, and APOE in macrophages through increased endogenous synthesis of 24(S),25-epoxycholesterol. J Biol Chem, 282, 5207-5216.

Calkin, A.C. and Tontonoz, P. (2010) Liver x receptor signaling pathways and atherosclerosis. Arterioscler Thromb Vasc Biol, 30, 1513-1518.

Larrede, S., Quinn, C.M., Jessup, W., Frisdal, E., Olivier, M., Hsieh, V., Kim, M.J., Van Eck, M., Couvert, P., Carrie, A., Giral, P., Chapman, M.J., Guerin, M. and Le Goff, W. (2009) Stimulation of cholesterol efflux by LXR agonists in cholesterol-loaded human macrophages is ABCA1-dependent but ABCG1-independent. Arterioscler Thromb Vasc Biol, 29, 1930-1936.

Schmitz, G. and Langmann, T. (2005) Transcriptional regulatory networks in lipid metabolism control ABCA1 expression. Biochim Biophys Acta, 1735, 1-19.

Torra, I.P., Ismaili, N., Feig, J.E., Xu, C.F., Cavasotto, C., Pancratov, R., Rogatsky, I., Neubert, T.A., Fisher, E.A. and Garabedian, M.J. (2008) Phosphorylation of liver X receptor alpha selectively regulates target gene expression in macrophages. Mol Cell Biol, 28, 2626-2636.

Whitney, K.D., Watson, M.A., Goodwin, B., Galardi, C.M., Maglich, J.M., Wilson, J.G., Willson, T.M., Collins, J.L. and Kliewer, S.A. (2001) Liver X receptor (LXR) regulation of the LXRalpha gene in human macrophages. $J$ Biol Chem, 276, 43509-43515.

Wojcicka, G., Jamroz-Wisniewska, A., Horoszewicz, K. and Beltowski, J. (2007) Liver X receptors (LXRs). Part I: structure, function, regulation of activity, and role in lipid metabolism. Postepy Hig Med Dosw (Online), 61, 736-759. 
Wong, J., Quinn, C.M. and Brown, A.J. (2006) SREBP-2 positively regulates transcription of the cholesterol efflux gene, ABCA1, by generating oxysterol ligands for LXR. Biochem J, 400, 485-491.

\section{Cholesterol influx}

Ikonen, E. (2008) Cellular cholesterol trafficking and compartmentalization. Nat Rev Mol Cell Biol, 9, 125-138.

Jia, L., Betters, J.L. and Yu, L. (2011) Niemann-pick C1-like 1 (NPC1L1) protein in intestinal and hepatic cholesterol transport. Annu Rev Physiol, 73, 239-259.

Moore, K.J., Rayner, K.J., Suarez, Y. and Fernandez-Hernando, C. (2010) microRNAs and cholesterol metabolism. Trends Endocrinol Metab, 21, 699-706.

Schroeder, F., Gallegos, A.M., Atshaves, B.P., Storey, S.M., McIntosh, A.L., Petrescu, A.D., Huang, H., Starodub, O., Chao, H., Yang, H., Frolov, A. and Kier, A.B. (2001) Recent advances in membrane microdomains: rafts, caveolae, and intracellular cholesterol trafficking. Exp Biol Med (Maywood), 226, 873-890.

Simons, K. and Ikonen, E. (2000) How cells handle cholesterol. Science, 290, 1721-1726.

\section{Cholesterol efflux}

Chapman, M.J., Le Goff, W., Guerin, M. and Kontush, A. (2010) Cholesteryl ester transfer protein: at the heart of the action of lipid-modulating therapy with statins, fibrates, niacin, and cholesteryl ester transfer protein inhibitors. Eur Heart J, 31, 149-164.

Degoma, E.M. and Rader, D.J. (2011) Novel HDL-directed pharmacotherapeutic strategies. Nat Rev Cardiol, 8, 266-277.

Duong, P.T., Weibel, G.L., Lund-Katz, S., Rothblat, G.H. and Phillips, M.C. (2008) Characterization and properties of pre beta-HDL particles formed by ABCA1-mediated cellular lipid efflux to apoA-I. J Lipid Res, 49, 1006-1014.

Ji, A., Meyer, J.M., Cai, L., Akinmusire, A., de Beer, M.C., Webb, N.R. and van der Westhuyzen, D.R. (2011) Scavenger receptor SR-BI in macrophage lipid metabolism. Atherosclerosis, 217, 106-112.

Maxfield, F.R. and Tabas, I. (2005) Role of cholesterol and lipid organization in disease. Nature, 438, 612-621.

McLaren, J.E., Michael, D.R., Ashlin, T.G. and Ramji, D.P. (2011) Cytokines, macrophage lipid metabolism and foam cells: Implications for cardiovascular disease therapy. Prog Lipid Res, 50, 331-347.

Taylor, J.M., Borthwick, F., Bartholomew, C. and Graham, A. (2010) Overexpression of steroidogenic acute regulatory protein increases macrophage cholesterol efflux to apolipoprotein AI. Cardiovasc Res, 86, 526-534.

Wroblewska, M. (2011) The origin and metabolism of a nascent pre-beta high density lipoprotein involved in cellular cholesterol efflux. Acta Biochim Pol. 


\section{UniProt References}

\begin{tabular}{l|c|l|l}
\hline PROTEIN NAME & UNIPROT ID & SYNONYMS & COMMENTS \\
\hline ABCA1 & O95477 & & \\
\hline ABCG1 & P45844 & & \\
\hline ACAT1 & P35610 & SOAT1 & \\
\hline ACAT2 & O75908 & SOAT2 & \\
\hline AMFR & Q9UKV5 & & \\
\hline AP2A1 & O95782 & & \\
\hline AP2B1 & P63010 & & \\
\hline AP2M1 & Q96CW1 & & \\
\hline AP2S1 & P53680 & & \\
\hline APOA1 & P02647 & & \\
\hline APOB & P04114 & & \\
\hline CAAX PROTEIN GENERIC1 & NA & & GENERIC \\
\hline CAAXPROTEIN GENERIC 2 & NA & & GENERIC \\
\hline CETP & P11597 & & \\
\hline CH25H & O95992 & & \\
\hline CLATHRIN & NA & & GENERIC \\
\hline CYP27A1 & Q02318 & & \\
\hline CYP3A4 & P08684 & & \\
\hline CYP51A1 & Q16850 & & \\
\hline CYP7A1 & P22680 & & \\
\hline DAB2 & P98082 & & \\
\hline DHCR24 & Q15392 & & \\
\hline DHCR7 & Q9UBM7 & & \\
\hline EBP & Q15125 & & \\
\hline FDFT1 & P37268 & & \\
\hline FDPS & P14324 & & \\
\hline FNTA & P49354 & & \\
\hline FNTB & P49356 & & \\
\hline GGPS1 & O95749 & & \\
\hline HDAC & NA & & GENERIC \\
\hline HMGCL & P35914 & & \\
\hline HMGCR & P04035 & & \\
\hline HMGCS1 & Q01581 & & \\
\hline HMGCS2 & P54868 & & \\
\hline HSD17B7 & P56937 & & \\
\hline IDI1 & Q13907 & & \\
\hline IDI2 & Q9BXS1 & & \\
\hline INSIG1 & O15503 & & \\
\hline INSIG2 & Q9Y5U4 & & \\
\hline LCAT & P04180 & & \\
\hline & & & \\
\hline
\end{tabular}




\begin{tabular}{|c|c|c|c|}
\hline PROTEIN NAME & UNIPROT ID & SYNONYMS & COMMENTS \\
\hline LDLR & P01130 & & \\
\hline LIPA & P38571 & & \\
\hline LSS & P48449 & & \\
\hline LXR & NA & & GENERIC \\
\hline LXRA & Q13133 & $\mathrm{NR} 1 \mathrm{H} 3$ & \\
\hline LXRB & P55055 & $\mathrm{NR} 1 \mathrm{H} 2$ & \\
\hline MVD & P53602 & & \\
\hline MVK & Q03426 & & \\
\hline NPC1 & 015118 & & \\
\hline NPC2 & P61916 & & \\
\hline $\mathrm{NSDHL}$ & Q15738 & & \\
\hline PGGT1B & P53609 & & \\
\hline PMVK & Q15126 & & \\
\hline RABGGTA & Q92696 & & \\
\hline RABGGTB & P53611 & & \\
\hline $\begin{array}{l}\text { RAB-XXCC/-XCXC/-CCXX PROTEIN } \\
\text { GENERIC }\end{array}$ & NA & & GENERIC \\
\hline REP1 & P24386 & & \\
\hline RXR & NA & & GENERIC \\
\hline RXRA & P19793 & & \\
\hline RXRB & P28702 & & \\
\hline$R \times R G$ & P48443 & & \\
\hline S1P & Q14703 & MBTPS1 & \\
\hline S2P & 043462 & MBTPS2 & \\
\hline SAR1-GTP & Q9NR31 & & \\
\hline SC4MOL & Q15800 & & \\
\hline SC5D & 075845 & & \\
\hline SCAP & Q12770 & & \\
\hline SEC23 & NA & & GENERIC \\
\hline SEC24 & NA & & GENERIC \\
\hline SQLE & Q14534 & & \\
\hline SR-B1 & Q8WTV0 & & \\
\hline SREBP2 & Q12772 & & \\
\hline TM7SF2 & 076062 & & \\
\hline UBE2G1 & P62253 & & \\
\hline UFD1 & Q92890 & UFD1L & \\
\hline
\end{tabular}

